\title{
Frequent loss of $17 p$, but no p53 mutations or protein overexpression in benign and malignant pheochromocytomas
}

\author{
Bart-Jeroen Petri ${ }^{1}$, Ernst-Jan M Speel ${ }^{2}$, Esther Korpershoek ${ }^{1}$, Sandra MH Claessen ${ }^{2}$, \\ Francien H van Nederveen ${ }^{1}$, Vivian Giesen ${ }^{2}$, Hilde Dannenberg ${ }^{1}$, Erwin van der Harst ${ }^{3}$, \\ Winand NM Dinjens ${ }^{1}$ and Ronald R de Krijger ${ }^{1}$ \\ ${ }^{1}$ Department of Pathology, Josephine Nefkens Institute, Erasmus MC-University Medical Center, Rotterdam, \\ The Netherlands; ${ }^{2}$ Department of Molecular Cell Biology, Research Institute Growth and Development \\ (GROW), University of Maastricht, Maastricht, The Netherlands and ${ }^{3}$ Department of Surgery, Medisch \\ Centrum Rijnmond Zuid, Rotterdam, The Netherlands
}

\begin{abstract}
Genetic changes in the tumorigenesis of sporadic pheochromocytomas are poorly understood, and there are no good markers to discriminate benign from malignant pheochromocytomas. p53 is a tumor suppressor gene and aberrations in this gene are frequently found in many tumor types. The role of $p 53$ in pheochromocytoma tumorigenesis is unclear, with some studies suggesting that p53 mutations can be used to discriminate benign from malignant pheochromocytomas while other studies do not find such an association. Because most of these investigations were hampered by small series of tumors and the use of varying methods, we have performed a comprehensive analysis of p53 aberrations in a large series of pheochromocytomas. Comparative genomic hybridization analysis of 31 benign and 20 malignant tumors showed loss of the p53 locus at chromosome 17p13.1 in 23/51 (45\%) cases, and most of these results were confirmed by fluorescence in situ hybridization. Forty-three tumors, including the malignant tumors and the tumors with loss of the p53 locus, were analyzed for p53 mutations in exons 5-8, but none were found. Furthermore, p53 immunohistochemistry on 35 cases revealed strong nuclear p53 expression in only two pheochromocytoma metastases, all other tumors being negative. We conclude that, although there is frequent loss of the p53 locus on 17p, the p53 gene does not appear to play a major role in pheochromocytoma tumorigenesis.
\end{abstract}

Modern Pathology (2008) 21, 407-413; doi:10.1038/modpathol.3801013; published online 25 January 2008

Keywords: pheochromocytoma; p53; malignant; tumorigenesis; immunohistochemistry

Pheochromocytomas are neuroendocrine tumors derived from chromaffin cells of the adrenal medulla. Extra-adrenal tumors of chromaffin tissue have recently been renamed sympathetic paragangliomas. Pheochromocytomas are usually benign $(90 \%)$, but there are no markers that can distinguish the remaining $10 \%$ malignant pheochromocytomas. Histologically confirmed metastases in places where chromaffin tissue does not normally occur, such as in bone, lung, liver, or lymph nodes, are the only accepted sign of malignancy. ${ }^{1}$

Correspondence: B-J Petri, MD, Department of Pathology, Erasmus MC-University Medical Center Rotterdam, Josephine Nefkens Institute, Room Be210A, PO Box 2040, Rotterdam, 3000 CA, The Netherlands.

E-mail: b.petri@erasmusmc.nl

Received 19 June 2007; revised 19 July 2007; accepted 1 August 2007; published online 25 January 2008
Whereas most pheochromocytomas occur sporadically, up to $24 \%$ of these tumors appear in familial cancer syndromes, such as multiple endocrine neoplasia 2, Von Hippel-Lindau disease, neurofibromatosis type 1 , and pheochromocytomaparaganglioma syndrome. ${ }^{2}$ In some sporadic pheochromocytomas, genes associated with the inherited tumor syndromes underlie tumorigenesis, but in the majority of sporadic pheochromocytomas molecular tumorigenesis is poorly understood. Loss of heterozygosity (LOH) and comparative genomic hybridization (CGH) studies performed by us and others have reported allelic losses at $1 \mathrm{p}, 3 \mathrm{pq}, 17 \mathrm{p}$, and $22 \mathrm{q}$, but corresponding genes have not been identified. ${ }^{3-6}$ Particularly $17 \mathrm{p}$, the chromosome arm where the p53 gene is located, is interesting to investigate knowing that aberrations in this gene are implicated in many inherited and sporadic forms of malignancy, such as colon, lung, brain, and breast tumors. ${ }^{7}$ 
p53 is functionally involved in guarding the stability of the genome. In case of DNA damage, it will downregulate the cell cycle and inhibit cell division. ${ }^{8}$ Mutations in and inactivation of one or both p53 alleles can promote tumorigenesis, whereas restoration of $p 53$ function results in tumor regression in in vivo animal models. ${ }^{9}$ Over the past decade, several studies have addressed the possible role of p53 in pheochromocytoma tumorigenesis. However, in many reports, only few pheochromocytomas were investigated. ${ }^{10-12}$ Five studies, including one from our own group, exclusively described the results of immunohistochemical staining. ${ }^{13-17}$ Other studies, examining p53 mutations with or without concomitant protein expression, included only benign or very few malignant pheochromocytomas, and generally did not show p53 gene mutations. ${ }^{18-20}$ In contrast, Yoshimoto et $a l^{21}$ described a relatively high frequency of singlestrand conformation polymorphism (SSCP) analysis abnormalities and p53 gene mutations in multiple and malignant pheochromocytomas from an Asian population.

To examine the involvement of p53 in pheochromocytoma development and malignant progression, we set out for CGH analysis of a uniquely large series of well-characterized benign and malignant pheochromocytomas. We identified chromosome alterations at chromosome 17 by using conventional CGH analysis and confirmed these data by using double-target fluorescence in situ hybridization (FISH) for the p53 gene and centromere loci. Subsequently, we used polymerase chain reaction (PCR) and SSCP analysis to detect p53 gene mutations in exons 5-8 and immunohistochemistry to visualize nuclear p53 overexpression.

\section{Materials and methods}

\section{Tissue Samples}

Tissue samples of pheochromocytomas ( $n=63$ from 48 patients) were collected from the pathology archive of the Departments of Pathology, Erasmus MC, Rotterdam ( $n=16)$, Radboud University Nijmegen $(n=43)$, and University Hospital Zurich $(n=4)$. Clinical and tumor data are listed in Table 1. All tumors were collected between 1978 and 2003. All malignant cases had histologically confirmed metastases, but only 12 of the latter are included in this study, because not all were available. There is no overlap between the tissue samples in this study and any of our previous studies, except for six samples that had been used for prior p53 immunostaining. ${ }^{5,15}$

\section{DNA Extraction}

DNA extraction was performed as described before. ${ }^{5,22}$ Genomic DNA from 50 frozen samples was isolated by homogenizing approximately $5 \mathrm{~mm}^{3}$ of each tissue sample prior to proteinase $\mathrm{K}$ treatment and DNA purification using the QIAamp DNA mini kit (Qiagen, Hilden, Germany). Genomic DNA from 13 paraffin-embedded tumors was isolated from $5-10-\mu$ m-thick tissue sections after deparaffinization. DNA quality was checked with agarose gel electrophoresis and quantified by spectrophotometry.

\section{CGH}

CGH was used to analyze genome-wide DNA copy number imbalances in 51 pheochromocytoma samples as described previously. ${ }^{23}$ This approach uses differentially labelled tumor and 'reference' DNA, which are competitively hybridized to normal metaphase chromosomes. The ratio of the fluorescence intensities detected is indicative of the relative DNA copy number in tumor vs reference DNA.

\section{FISH}

Touch preparations of $n=29$ frozen pheochromocytomas and $4-\mu \mathrm{m}$-thick tissue sections of $n=4$ routinely fixed, paraffin-embedded tumors were subjected to FISH $(n=32)$ as described previously. $^{22,23} \mathrm{~A}$ combination of centromere 17 (p17H8) and a PAC probe containing the p53 gene on chromosome 17p13.1, labelled with digoxigenin and biotin, respectively, was used for hybridization. Digoxigenin was detected by sheep anti-digoxigenin fluorescein (Roche) and biotin by two layers of avidin-rhodamine connected by a biotinylated goat anti-avidin antibody (Vector). Probe visualization and nuclear counterstaining were carried out as described for CGH, and slide evaluation and signal scoring to detect DNA copy number gain and losses were performed as described previously. ${ }^{22,24}$

\section{PCR-SSCP}

Exons 5-8 of the p53 gene, including the exonintron boundaries, were investigated by PCR-SSCP in $n=43$ pheochromocytoma samples. As controls, DNA samples from normal individuals were used. In addition, DNA from the prostate carcinoma cell lines PC-3 and Du-145, and from the colorectal carcinoma cell lines Colo-320 and HT-29, with known p53 mutations in exons 5, 6, 7, and 8, respectively, served as positive controls, shown by van Nederveen et al. ${ }^{25}$ The DNA isolated from routine formalin-fixed, paraffin-embedded tissues is highly degraded; therefore, we used small amplicons $(<200 \mathrm{bp})$ with overlapping primers for each exon to maximize chances of detecting mutations whenever they would be present. The primers are listed in Table 2. PCR was performed with 1-3 $\mu$ l of isolated DNA in a final reaction volume of $15 \mu \mathrm{l}$ 


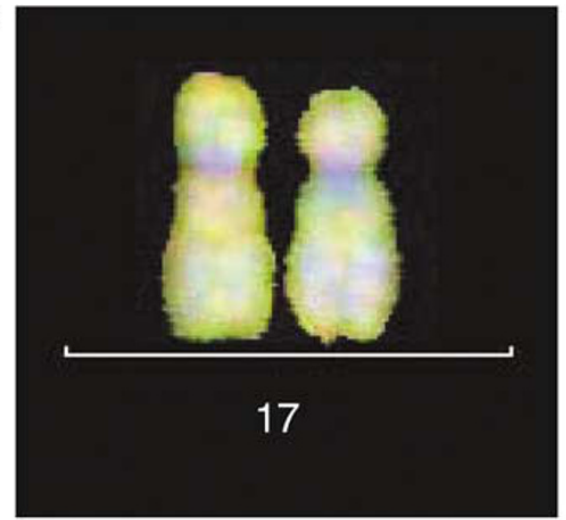

b

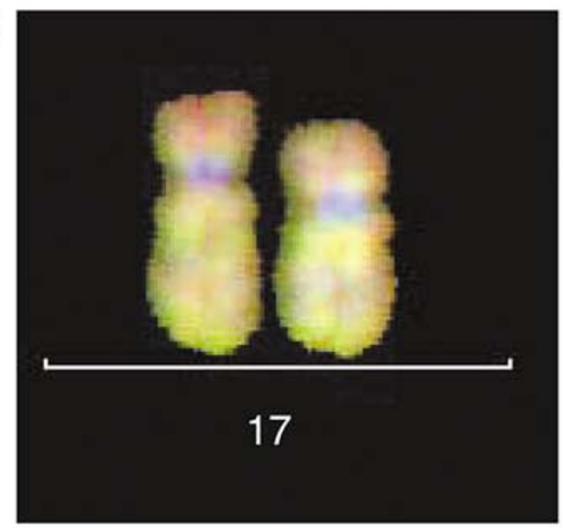

C

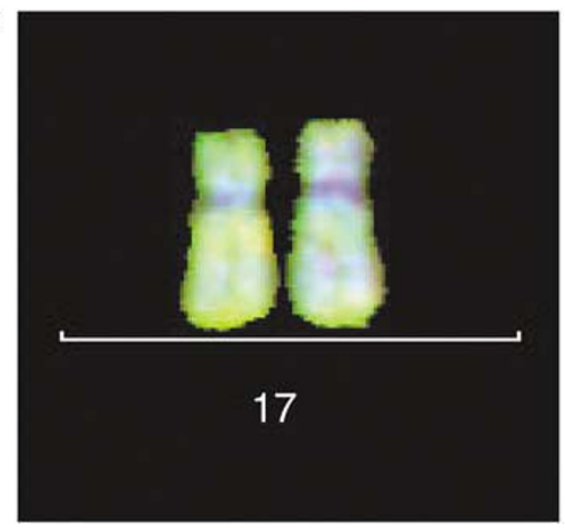

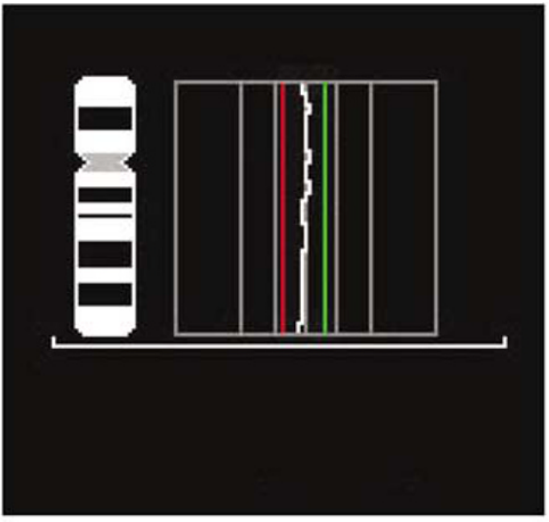
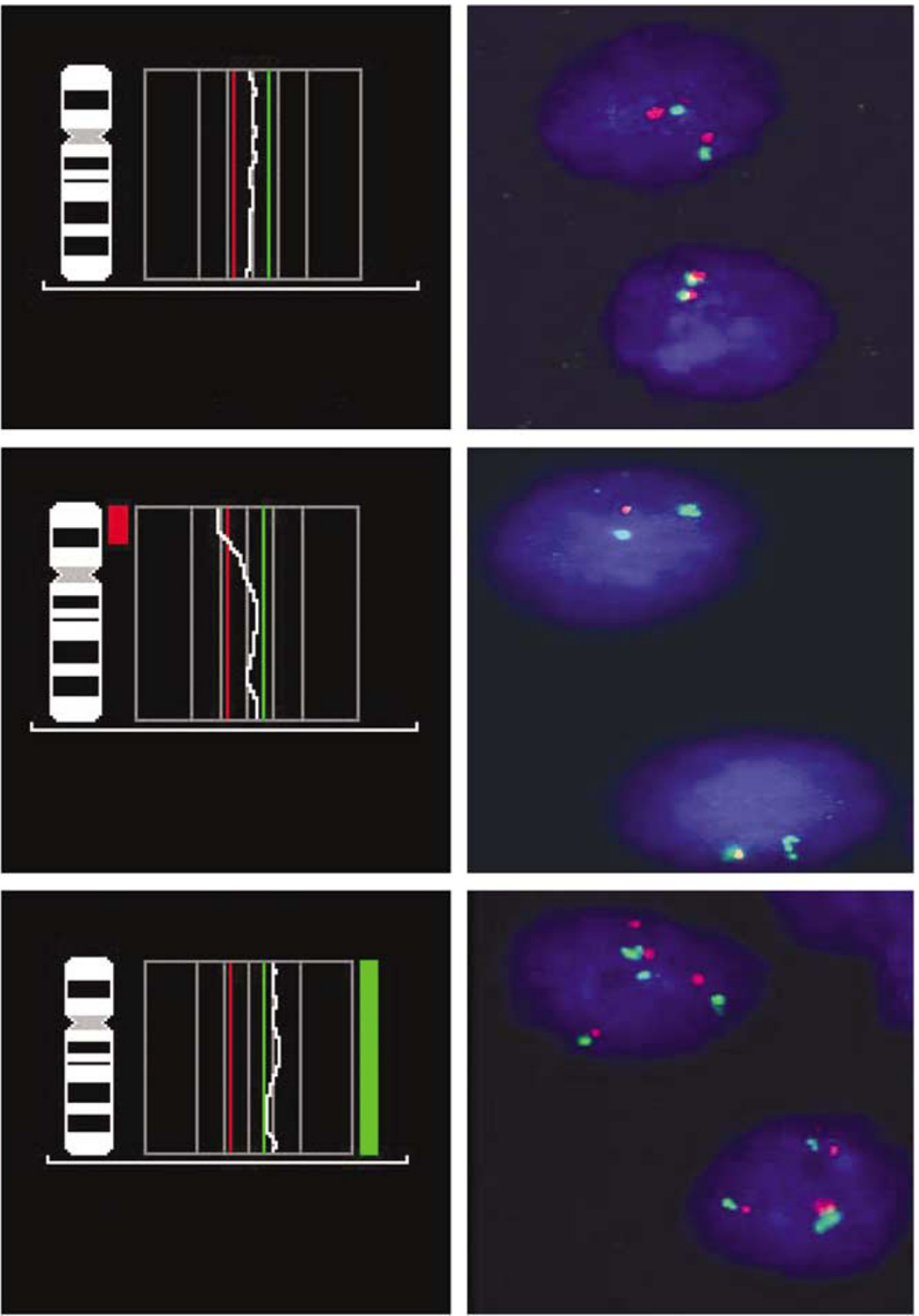

Figure 1 Representative results of chromosome 17 CGH analysis confirmed by FISH of the p53 locus in three cases of malignant PCC (a) Malignant PCC (case 15), not showing loss or gain in CGH and FISH analysis. (b) Malignant PCC (case 8) with loss of 17p in the CGH analysis, including the p53 gene locus, also showing loss in FISH. (c) Malignant PCC (case 13) showing gain of chromosome 17 in the CGH analysis and multiple p53 gene loci by FISH.

containing, in mmol/l, $\mathrm{MgCl}_{2}$ 1.5, dATP 0.02, dGTP 0.2 , dTTP 0.2 , and dCTP $0.2,\left[\alpha^{32} \mathrm{P}\right] \mathrm{dATP} 0.8 \mu \mathrm{Ci}$ (Amersham, Buckinghamshire, UK), $20 \mathrm{pmol}$ of each primer, and $0.2 \mathrm{U}$ of Taq polymerase (Promega, Madison, WI, USA). PCR was performed for 35 cycles (denaturing at $95^{\circ} \mathrm{C}$ for $30 \mathrm{~s}$, annealing at $55^{\circ} \mathrm{C}$ for $45 \mathrm{~s}$, and extension at $72^{\circ} \mathrm{C}$ for $1 \mathrm{~min}$ ) in a Biometra thermocycler (Biometra, Göttingen, Germany). A final extension was carried out at $72^{\circ} \mathrm{C}$ for $10 \mathrm{~min}$. PCR products were diluted with loading buffer (95\% formamide, $10 \mathrm{mmol} / \mathrm{l}$ EDTA ( $\mathrm{pH}$ 8.0), $0.025 \%$ bromophenol blue, and $0.025 \%$ xylene cyanol), and denatured at $95^{\circ} \mathrm{C}$ for $10 \mathrm{~min}$.
The solution was chilled on ice and $4 \mu \mathrm{l}$ was loaded on an $8 \%$ polyacrylamide gel (acrylamide to bisacrylamide, 49:1) containing $10 \%$ glycerol. Electrophoresis was performed at $8 \mathrm{~W}$ for $16 \mathrm{~h}$ at room temperature. Gels were vacuum dried at $80^{\circ} \mathrm{C}$ and exposed to X-ray films.

\section{Immunohistochemistry}

p53 immunohistochemistry was performed using a monoclonal mouse antibody directed against normal and mutated p53 (Do-7, Dako, Glostrup, Denmark). 
410
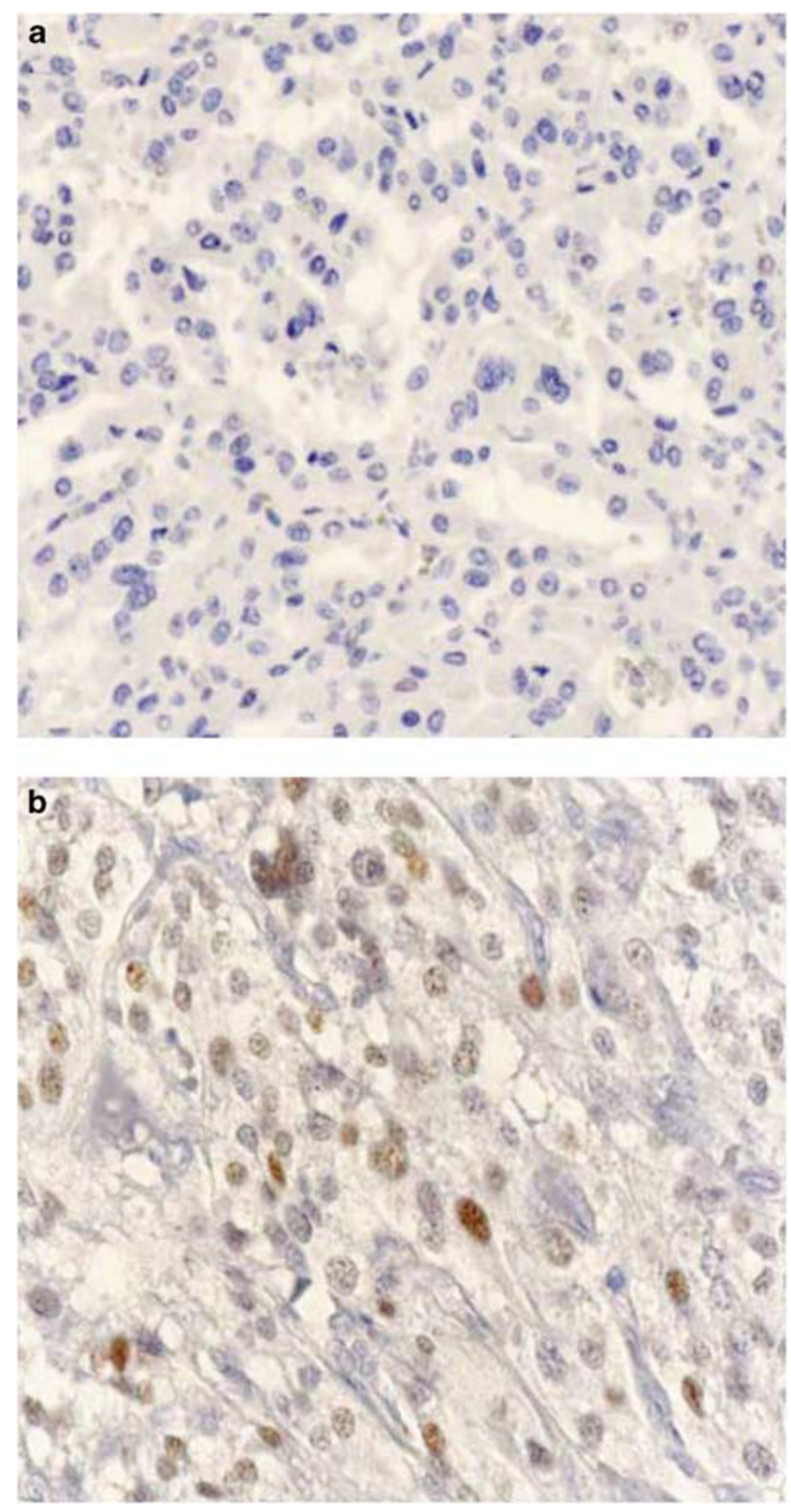

Figure 2 Representative results of p53 immunohistochemistry in malignant PCC. (a) Primary tumor of a malignant PCC (case 6) not showing nuclear overexpression of p53 protein (score 0). (b) Malignant PCC (case 7) showing the corresponding metastasis of the primary tumor shown in (a) with positive nuclear immunostaining for p53 (score 6).

Tissue samples of 36 pheochromocytomas were formalin-fixed and embedded in paraffin. Sections of $4 \mu \mathrm{m}$ thickness were cut and mounted on Superfrost Plus slides. The sections were deparaffinized, dehydrated, exposed to microwave heating (in Tris/ EDTA $\mathrm{pH} 9.0$ ) at $100^{\circ} \mathrm{C}$ for $15 \mathrm{~min}$, rinsed with tap water followed by incubation in $\mathrm{H}_{2} \mathrm{O}_{2} 30 \%$ /PBS 1:10 for $15 \mathrm{~min}$. The p53 antibody was diluted 1:100 with normal antibody diluents (Klinipath, Duiven, The Netherlands), and slides were incubated with $150 \mu \mathrm{l}$ per slide for $30 \mathrm{~min}$, followed by rinsing with Tris/
Table 1 Clinical and tumor data of 63 PCC from 48 patients

\begin{tabular}{lc}
\hline Sex $(\mathrm{M} / \mathrm{F})$ & $19 / 29$ \\
Average age (years) & 45.7 (range 23-72) \\
Malignant/benign & $18 / 30$ \\
Metastases & 12 \\
Sporadic cases & 39 \\
Familial cases & 8 \\
${ }^{*}$ MEN2a & 6 \\
${ }^{*}$ NF1 & 2 \\
Adrenal cases & 41 \\
Extra-adrenal cases & 7 (malignant/benign $4 / 3$ ) \\
Unilateral cases & 43 \\
Bilateral cases & 5 (all MEN 2a) \\
\end{tabular}

*Indicates that of the 8 familial cases, there are 6 MEN2 cases and 2 NF1 cases.

Table $2 p 53$ primer sets exons 5-8 for SSCP

\begin{tabular}{llll}
\hline & Forward $5^{\prime} \rightarrow 3^{\prime}$ & Reverse $5^{\prime} \rightarrow 3^{\prime}$ & Size \\
\hline Exon 5-I & cctgactttcaactcttgctc & actgcttgtagatggccatg & $158 \mathrm{bp}$ \\
Exon 5-II & cagctgtgggttgattccac & ctggggaccctgggcaac & $176 \mathrm{bp}$ \\
Exon 6-I & agcctctgattcctcactg & gaccaccacactatgtcga & $127 \mathrm{bp}$ \\
Exon 6-II & ccctcagcatcttatccga & ccactgacaaccaccctt & $159 \mathrm{bp}$ \\
Exon 7-I & aggcgcactggcctcatctt & tccagtgtgatgatggtgagg & $141 \mathrm{bp}$ \\
Exon 7-II & catgtgtaacagttcctgcatg & gcggcaagcagaggctgg & $135 \mathrm{bp}$ \\
Exon 8-I & ccttactgcctcttgcttctc & cttgcggagattctcttcctc & $130 \mathrm{bp}$ \\
Exon 8-II & tggtgcctgtcctgggagag & ctccaccgcttcttgtcct & $127 \mathrm{bp}$
\end{tabular}

Tween 0.5\%, pH 8.0. Dako ChemMate Envision HRP was applied for $30 \mathrm{~min}$ ( $150 \mu \mathrm{l}$, Dako envision kit), followed by rinsing with Tris/Tween $0.5 \%$, pH 8.0. Diaminobenzidine tetrahydrochloride $(150 \mu \mathrm{l}$, Dako envision kit) was applied twice, without rinsing, and rinsed with tap water. Slides were counterstained with Harris haematoxylin for $1 \mathrm{~min}$ and rinsed with tap water. Slides were rehydrated and covered. In the negative control reactions, the primary antibodies were omitted from the dilution buffer. A p53-positive breast carcinoma was used as positive control. Scoring of p53 staining was based on a method described by Sinicrope et al. ${ }^{26}$ Two independent observers scored the tumors based on intensity and the percentage of nuclei showing immunostaining. Intensity is scored in three groups: weak $=1$, moderate $=2$, and strong $=3$. Percentages are divided in five groups: $\leq 5 \%=0,5-25 \%=1$, $25-50 \%=2,50-75 \%=3$, and $\geq 75 \%=4$. A multiplied score of $\geq 6$ was considered positive staining and a score $<6$ was considered negative.

\section{Results}

\section{CGH Findings}

Table 3 shows the losses and gains on chromosome 17 of the 51 tumor ( 31 benign and 20 malignant) samples that were examined by CGH. We found CGH abnormalities on chromosome 17 in 29/51 $(57 \%)$ tumors, including $23 / 51(45 \%)$ at the $p 53$ gene locus at 17p13.1. In 18 of these 23 cases (78\%) 
Table 3 Results of CGH analysis, FISH, SSCP analysis, and immunohistochemistry in benign PCC

\begin{tabular}{|c|c|c|c|c|c|}
\hline Samples & Patients & Characteristics & $\begin{array}{c}C G H \\
17 p\end{array}$ & $\begin{array}{c}\text { FISH } \\
\text { p53 }\end{array}$ & $S S C P$ \\
\hline 1 & 1 & $\mathrm{~F} / 62 \mathrm{sp} / \mathrm{adr} / \mathrm{u}$ & - & - & 0 \\
\hline 2 & 2 & $\mathrm{M} / 30 \mathrm{sp} / \mathrm{adr} / \mathrm{u}$ & - & - & 0 \\
\hline 3 & 3 & F/41 sp/adr/u & - & - & 0 \\
\hline 4 & 4 & $\mathrm{~F} / 24 \mathrm{n} / \mathrm{adr} / \mathrm{u}$ & - & - & 0 \\
\hline 5 & 5 & M/66 sp/adr/u & - & - & 0 \\
\hline 6 & 6 & $\mathrm{M} / 49 \mathrm{~m} / \mathrm{adr} / \mathrm{bi}$ & - & - & 0 \\
\hline 7 & 7 & $\mathrm{M} / 42 \mathrm{sp} / \mathrm{adr} / \mathrm{u}$ & - & - & 0 \\
\hline 8 & 8 & $\mathrm{M} / 47 \mathrm{sp} / \mathrm{ea} / \mathrm{u}$ & - & - & 0 \\
\hline 9 & 9 & F/69 sp/adr/u & - & - & 0 \\
\hline 10 & 10 & F/37 sp/adr/u & - & - & 0 \\
\hline 11 & 11 & $\mathrm{M} / 41 \mathrm{sp} / \mathrm{adr} / \mathrm{u}$ & - & - & - \\
\hline 12 & 12 & F/30 sp/adr/u & - & - & 0 \\
\hline 13 & 13 & $\mathrm{~F} / 56 \mathrm{sp} / \mathrm{ea} / \mathrm{u}$ & 0 & - & - \\
\hline 14 & 14 & $\mathrm{M} / 41 \mathrm{sp} / \mathrm{adr} / \mathrm{u}$ & 0 & - & 0 \\
\hline 15 & 15 & $\mathrm{~F} / 33 \mathrm{sp} / \mathrm{adr} / \mathrm{u}$ & $\bigcirc$ & 0 & $\bigcirc$ \\
\hline 16 & 16 & $\mathrm{M} / 72 \mathrm{~m} / \mathrm{adr} / \mathrm{bi} \mathrm{I}$ & $\mathrm{OO}$ & 0 & - \\
\hline 17 & & II & 0 & - & 0 \\
\hline 18 & 17 & $\mathrm{M} / 40 \mathrm{~m} / \mathrm{adr} / \mathrm{u}$ & $\bigcirc \bigcirc$ & $\bigcirc$ & O \\
\hline 19 & 18 & $\mathrm{M} / 53 \mathrm{~m} / \mathrm{adr} / \mathrm{bi} \mathrm{I}$ & $\bigcirc \bigcirc$ & $\bigcirc$ & $\bigcirc$ \\
\hline 20 & & II & 0 & - & - \\
\hline 21 & 19 & F/33 sp/adr/u & 00 & O & - \\
\hline 22 & 20 & F/44 sp/adr/u & 0 & 0 & - \\
\hline 23 & 21 & $\mathrm{M} / 24 \mathrm{~m} / \mathrm{adr} / \mathrm{u}$ & O & O & - \\
\hline 24 & 22 & M/58 sp/adr/u & 0 & 0 & - \\
\hline 25 & 23 & $\mathrm{~F} / 53 \mathrm{n} / \mathrm{adr} / \mathrm{u}$ & $\bigcirc$ & $\bigcirc$ & - \\
\hline 26 & 24 & $\mathrm{M} / 53 \mathrm{sp} / \mathrm{adr} / \mathrm{u}$ & $\bigcirc$ & - & O \\
\hline 27 & 25 & F/59 sp/adr/u & 0 & 0 & - \\
\hline 28 & 26 & F/49 sp/adr/u & O & O & - \\
\hline 29 & 27 & F/48 sp/adr/u & 0 & 0 & - \\
\hline 30 & 28 & $\mathrm{~F} / 24 \mathrm{~m} / \mathrm{adr} / \mathrm{bi} \mathrm{I}$ & $\bigcirc$ & $\bigcirc$ & - \\
\hline 31 & & /27 II & 0 & - & - \\
\hline 32 & 29 & $\mathrm{~F} / 59 \mathrm{~m} / \mathrm{adr} / \mathrm{bi}$ & - & - & - \\
\hline 33 & 30 & $\mathrm{M} / 43 \mathrm{sp} / \mathrm{adr} / \mathrm{u}$ & - & - & - \\
\hline
\end{tabular}

In CGH analysis, $\bigcirc$ represents 'no gain or loss,' $\bullet$ is 'loss,' and $\bigcirc \bigcirc$ means 'gain' of chromosome 17. In FISH analysis, $\bigcirc$ is 'retention of heterozygosity,' - means 'loss of heterozygosity,' and $\bigcirc \bigcirc$ represents 'gain' of the p53 locus on chromosome 17. In SSCP, $\bigcirc$ means no mutation. In immunohistochemistry, $\bigcirc$ represents 'no overexpression' and $\bullet$ means p53 protein overexpression. In all four techniques, - means that these samples are not examined. $\mathrm{M}=$ male; $\mathrm{F}=$ female; $\mathrm{sp}=$ sporadic $; \mathrm{m}=\mathrm{men} ; \mathrm{n}=$ neurofibromatosis; $\mathrm{adr}=$ adrenal; $\mathrm{ea}=$ extra-adrenal; $\mathrm{u}=$ unilateral; $\mathrm{bi}=$ bilateral; $\mathrm{LN}=$ lymph node

there was loss, and in 5 of $23(22 \%)$ we found gain of chromosomal material.

\section{Confirmation of CGH Data by FISH}

FISH analysis on 29 touch preparations and 4 paraffin-embedded tissue sections confirmed the CGH results at the p53 locus. We found abnormalities in the FISH analysis in 16/33 (48\%) cases, including 14/33 (42\%) cases with loss of the p53 locus and $2 / 33(6 \%)$ with gain of the p53 locus. There was almost complete concordance between the FISH and CGH data for those samples that were analyzed with both techniques, except for the benign cases $13,14,15$, and 17 in which there was loss in the FISH analysis but not in the CGH and benign cases 16, 18, 19, and 21 in which we observed gain in the CGH but not in the FISH
Table 4 Results of CGH analysis, FISH, SSCP analysis, and immunohistochemistry in malignant PCC

\begin{tabular}{|c|c|c|c|c|c|}
\hline Samples & Patients & Characteristics & $\begin{array}{c}C G H \\
17 p\end{array}$ & $\begin{array}{c}\text { FISH } \\
\text { p53 }\end{array}$ & SSCP \\
\hline 1 & 1 & $\mathrm{~F} / 47 \mathrm{sp} / \mathrm{adr} / \mathrm{u}$ & - & ○ & 0 \\
\hline 2 & 2 & $\mathrm{~F} / 65 \mathrm{sp} / \mathrm{adr} / \mathrm{u}$ & • & • & 0 \\
\hline 3 & 3 & $\mathrm{~F} / 70 \mathrm{sp} / \mathrm{adr} / \mathrm{u}$ & - & - & 0 \\
\hline 4 & 4 & F/56 sp/adr/u & ○ & - & $\bigcirc$ \\
\hline 5 & & meta & - & - & 0 \\
\hline 6 & 5 & $\mathrm{~F} / 30 \mathrm{sp} / \mathrm{ea} / \mathrm{u}$ & - & - & - \\
\hline 7 & & Meta intercost I & 0 & - & 0 \\
\hline 8 & & Meta intercost II & - & - & 0 \\
\hline 9 & 6 & $\mathrm{M} / 70 \mathrm{sp} / \mathrm{adr} / \mathrm{u}$ & - & - & - \\
\hline 10 & & Meta LN & - & - & 0 \\
\hline 11 & 7 & $\mathrm{~F} / 53 \mathrm{sp} / \mathrm{ea} / \mathrm{u}$ & - & - & - \\
\hline 12 & & Meta & 0 & - & 0 \\
\hline 13 & 8 & $\mathrm{~F} / 27 \mathrm{sp} / \mathrm{adr} / \mathrm{u}$ & ○ & 00 & 0 \\
\hline 14 & 9 & F/32 sp/adr/u & 0 & - & 0 \\
\hline 15 & & Meta LN I & 0 & 0 & 0 \\
\hline 16 & & Meta LN II & $\bigcirc$ & 一 & $\bigcirc$ \\
\hline 17 & 10 & $\mathrm{M} / 32 \mathrm{sp} / \mathrm{ea} / \mathrm{u}$ & 0 & 0 & 0 \\
\hline 18 & 11 & $\mathrm{M} / 36 \mathrm{sp} / \mathrm{adr} / \mathrm{u}$ & 0 & 0 & 0 \\
\hline 19 & & Meta LN & - & - & $\bigcirc$ \\
\hline 20 & 12 & $\mathrm{~F} / 23 \mathrm{sp} / \mathrm{adr} / \mathrm{u}$ & 0 & 0 & 0 \\
\hline 21 & & Meta bone & - & - & 0 \\
\hline 22 & 13 & $\mathrm{~F} / 62 \mathrm{sp} / \mathrm{adr} / \mathrm{u}$ & 0 & 0 & 0 \\
\hline 23 & 14 & $\mathrm{M} / 42 \mathrm{sp} / \mathrm{adr} / \mathrm{u}$ & 0 & - & 0 \\
\hline 24 & 15 & $\mathrm{M} / 42 \mathrm{sp} / \mathrm{adr} / \mathrm{u}$ & - & - & 0 \\
\hline 25 & 16 & F/39 sp/adr/u & - & - & 0 \\
\hline 26 & & /49 meta LN & 0 & - & 0 \\
\hline 27 & 17 & $\mathrm{~F} / 45 \mathrm{sp} / \mathrm{adr} / \mathrm{u}$ & 0 & - & 0 \\
\hline 28 & & Meta LN & - & 0 & - \\
\hline 29 & 18 & F/32 sp/adr/u & - & - & 0 \\
\hline 30 & & Meta liver & 0 & - & 0 \\
\hline
\end{tabular}

In CGH analysis, $\bigcirc$ represents 'no gain or loss,' $\bigcirc$ is 'loss,' and $\bigcirc \bigcirc$ means 'gain' of chromosome 17. In FISH analysis, $\bigcirc$ is 'retention of heterozygosity,' means 'loss of heterozygosity,' and $\bigcirc \bigcirc$ represents 'gain' of the p53 locus on chromosome 17. In SSCP, $\bigcirc$ means no mutation. In immunohistochemistry, $\bigcirc$ represents 'no overexpression' and means p53 protein overexpression. In all four techniques, - means that these samples are not examined. $\mathrm{M}=$ male; $\mathrm{F}=$ female $\mathrm{sp}=$ sporadic $\quad \mathrm{m}=$ men; $\mathrm{n}=$ neurofibromatosis; $\mathrm{adr}=$ adrenal; ea = extra-adrenal; $\mathrm{u}=$ unilateral; $\mathrm{bi}=$ bilateral; Meta $=$ metastasis; $\mathrm{LN}=$ lymph node.

analysis. The results are shown in Tables 3 and 4 and a representative result of $\mathrm{CGH}$ and FISH analysis is shown in Figure 1.

\section{PCR-SSCP analysis}

PCR-SSCP analysis was performed on 43 samples to examine sequence abnormalities in exons $5-8$ of the p53 gene. No band shifts were found at SSCP, indicating that there were no mutations in $n=17$ benign and $n=26$ malignant pheochromocytomas, as our positive control yielded the expected results. The results are shown in Tables 3 and 4 .

\section{Immunohistochemistry}

Immunohistochemical staining was performed on 36 samples to analyze whether there was overexpression of the p53 protein. Two of 36 samples 
(6\%) showed overexpression (score $\geq 6$ ), whereas all other samples, including the corresponding primary tumor of one of these two metastases, were negative (score $\leq 5)$ (Figure 2). One of these two positive samples was available for SSCP analysis, but did not show a band shift, nor did we find loss in the CGH analysis of the other primary tumor. The results are summarized in Tables 3 and 4.

\section{Discussion}

In this study, we have performed a comprehensive analysis of a large series of benign and malignant pheochromocytomas to detect abnormalities in p53 at the DNA and protein level using a variety of techniques. Although we found a loss rate of $45 \%$ in CGH analysis at the $p 53$ locus, which was confirmed by FISH analysis, we could not detect gene mutations in the p53 exons $5-8$, nor did we find a high frequency of p53 protein overexpression by immunohistochemistry, with only two metastases showing nuclear immunostaining. This leads us to suggest that p53 abnormalities apparently do not appear to play a major role in the tumorigenesis of benign and malignant pheochromocytomas, except for a possible minor role in metastatic progression. p53 abnormalities thus cannot be used for the distinction between benign and malignant pheochromocytomas.

Until now, the molecular mechanisms underlying sporadic pheochromocytoma tumorigenesis have largely remained elusive. Because of its frequent involvement in carcinogenesis, $p 53$ has been the topic of several investigations, employing a range of techniques. However, most of these studies were limited to a single technique or considered only small numbers of tumors. Our study is the first to specifically address loss of $17 \mathrm{p}$, including the $p 53$ locus, by conventional CGH analysis. This analysis, which we confirmed by FISH, was performed in the context of a genome-wide CGH study, which is the topic of a separate paper. In four cases, we observed a discrepancy between the CGH and the FISH analysis, identifying loss by FISH but no alterations by CGH. This may be due to the fact that not all deletions are picked up in CGH analysis due to its limitations in resolution. ${ }^{23}$ The observed loss rate of $45 \%$ is in accordance with our previous work, where we found $31 \%$ loss in a series of 29 pheochromocytomas, and with $\mathrm{LOH}$ analyses performed by others, which showed loss rates between 18 and $24 \% .^{5,18,27}$ In five pheochromocytomas (10\%), gain of $17 p$ was found in CGH, although copy number gain could only be confirmed in two instances by FISH analysis. This may most probably be due to heterogeneity in the tumors or may be partly due to the pheochromocytomas being rather hypodiploid.

In the majority of cases in which we found loss of $17 \mathrm{p}$ at the CGH analysis and in almost all malignant pheochromocytomas, we performed mutation analysis of exons 5-8 using SSCP analysis, which allows the detection of over $90 \%$ of mutations. However, we did not find a single mutation in our analysis, which is in accordance with several previous studies. ${ }^{18,20}$ However, two Asian studies reported $83 \%$ (5/6) and 40\% (4/10) p53 mutations, respectively. ${ }^{10,21}$ The reason for the discrepancy between these two groups of studies is not known, but may be related to geographical factors. Alternatively, we cannot entirely exclude the fact that mutations are present in other parts of the p53 gene, but it is known that more than $95 \%$ of mutations occur in exons $5-8 .^{7}$

In normal cells, nuclear p53 expression is usually below the detection level of immunohistochemistry. Mutant $p 53$, because of its longer half-life, and cellular stress can induce overexpression, resulting in positive nuclear immunostaining. In the present study, we did not find a single positive case in the entire group of primary pheochromocytomas. It must be noted that we employed very strict criteria before a tumor was scored as positive (see Materials and methods for scoring system). This is based on the notion that for p53 to play a major role in tumorigenesis, whether in pheochromocytomas or in other tumors, a large proportion of cells should show moderate or strong immunostaining to be considered physiologically relevant. In addition, in our experience, no p53 mutations, for example in intestinal or breast tumors, are found if only weak or focal staining is present (Dinjens, personal communication). In many of the studies on p53 immunohistochemistry in pheochromocytomas that have been published so far, a variety of scoring systems have been used, usually yielding a low percentage of cases that were considered positive. Whenever cases were considered positive, these were frequently malignant pheochromocytomas or metastases thereof, which is in line with our finding of two metastases showing p53 overexpression. The corresponding primary tumors, however, were negative.

Taken together, we have found a relatively high frequency of loss at the $p 53$ gene locus on chromosome $17 \mathrm{p}$, without concomitant p53 mutations or signs of protein overexpression by immunohistochemistry. These results were similar between pheochromocytomas and sympathetic paragangliomas. This suggests that $p 53$ does not appear to play a major role either in tumorigenesis or in the clinical behavior of human pheochromocytomas. Because of the relatively high frequency of $17 p$ loss, one may hypothesize the existence of other tumor suppressor genes on this chromosomal arm, which may be involved in pheochromocytomas. An example of these is described in patients with breast cancer and endocrine pancreatic tumors. ${ }^{28,29}$ However, it cannot be excluded that loss of $17 \mathrm{p}$ is the result of stochastic accumulation of genetic abnormalities in pheochromocytomas. 


\section{Acknowledgement}

This work was supported in part by a grant from Mrace, Erasmus MC-University Medical Center, Rotterdam, The Netherlands.

\section{References}

1 Lenders JW, Eisenhofer G, Mannelli M, et al. Phaeochromocytoma. Lancet 2005;366:665-675.

2 Neumann HP, Bausch B, McWhinney SR, et al. Germline mutations in nonsyndromic pheochromocytoma. N Engl J Med 2002;346:1459-1466.

3 Bender BU, Gutsche M, Glasker S, et al. Differential genetic alterations in von Hippel-Lindau syndromeassociated and sporadic pheochromocytomas. J Clin Endocrinol Metab 2000;85:4568-4574.

4 Edstrom E, Mahlamaki E, Nord B, et al. Comparative genomic hybridization reveals frequent losses of chromosomes $1 \mathrm{p}$ and $3 \mathrm{q}$ in pheochromocytomas and abdominal paragangliomas, suggesting a common genetic etiology. Am J Pathol 2000;156:651-659.

5 Dannenberg $\mathrm{H}$, Speel EJ, Zhao J, et al. Losses of chromosomes $1 \mathrm{p}$ and $3 \mathrm{q}$ are early genetic events in the development of sporadic pheochromocytomas. Am J Pathol 2000;157:353-359.

6 Jarbo C, Buckley PG, Piotrowski A, et al. Detailed assessment of chromosome 22 aberrations in sporadic pheochromocytoma using array-CGH. Int J Cancer 2006;118:1159-1164.

7 Hollstein M, Sidransky D, Vogelstein B, et al. p53 mutations in human cancers. Science 1991;253:49-53.

8 Levine AJ, Momand J, Finlay CA. The p53 tumour suppressor gene. Nature 1991;351:453-456.

9 Ventura A, Kirsch DG, McLaughlin ME, et al. Restoration of p53 function leads to tumour regression in vivo. Nature 2007;445:661-665.

10 Lin SR, Lee YJ, Tsai JH. Mutations of the p53 gene in human functional adrenal neoplasms. J Clin Endocrinol Metab 1994;78:483-491.

11 Reincke M, Wachenfeld C, Mora P et al. p53 mutations in adrenal tumors: Caucasian patients do not show the exon 4 'hot spot' found in Taiwan. J Clin Endocrinol Metab 1996;81:3636-3638.

12 Ballantine DM, Klemm SA, Tunny TJ, et al. PCR-SSCP analysis of the p53 gene in tumours of the adrenal gland. Clin Exp Pharmacol Physiol 1996;23:582-583.

13 Wang DG, Johnston CF, Anderson N, et al. Overexpression of the tumour suppressor gene p53 is not implicated in neuroendocrine tumour carcinogenesis. J Pathol 1995;175:397-401.

14 Lam KY, Lo CY, Wat NM, et al. The clinicopathological features and importance of p53, Rb, and mdm2 expression in phaeochromocytomas and paragangliomas. J Clin Pathol 2001;54:443-448.

15 de Krijger RR, van der Harst E, van der Ham F, et al. Prognostic value of p53, bcl-2, and c-erbB-2 protein expression in phaeochromocytomas. J Pathol 1999; 188:51-55.

16 Gupta D, Shidham V, Holden J, et al. Prognostic value of immunohistochemical expression of topoisomerase alpha II, MIB-1, p53, E-cadherin, retinoblastoma gene protein product, and HER-2/neu in adrenal and extraadrenal pheochromocytomas. Appl Immunohistochem Mol Morphol 2000;8:267-274.

17 Salmenkivi K, Heikkila P, Haglund C, et al. Lack of histologically suspicious features, proliferative activity, and p53 expression suggests benign diagnosis in phaeochromocytomas. Histopathology 2003;43:62-71.

18 Herfarth KK, Wick MR, Marshall HN, et al. Absence of TP53 alterations in pheochromocytomas and medullary thyroid carcinomas. Genes Chromosomes Cancer 1997;20:24-29.

19 Yana I, Nakamura T, Shin E, et al. Inactivation of the p53 gene is not required for tumorigenesis of medullary thyroid carcinoma or pheochromocytoma. Jpn J Cancer Res 1992;83:1113-1116.

20 Dahia PL, Aguiar RC, Tsanaclis AM, et al. Molecular and immunohistochemical analysis of P53 in phaeochromocytoma. Br J Cancer 1995;72:1211-1213.

21 Yoshimoto T, Naruse M, Zeng Z, et al. The relatively high frequency of p53 gene mutations in multiple and malignant phaeochromocytomas. J Endocrinol 1998;159:247-255.

22 Speel EJ, Scheidweiler AF, Zhao J, et al. Genetic evidence for early divergence of small functioning and nonfunctioning endocrine pancreatic tumors: gain of 9Q34 is an early event in insulinomas. Cancer Res 2001;61:5186-5192.

23 Jonkers YM, Claessen SM, Perren A, et al. Chromosomal instability predicts metastatic disease in patients with insulinomas. Endocr Relat Cancer 2005;12: 435-447.

24 Barghorn A, Komminoth P, Bachmann D, et al. Deletion at 3p25.3-p23 is frequently encountered in endocrine pancreatic tumours and is associated with metastatic progression. J Pathol 2001;194:451-458.

25 van Nederveen FH, Dannenberg H, Sleddens HF, et al. p53 alterations and their relationship to SDHD mutations in parasympathetic paragangliomas. Mod Pathol 2003;16:849-856.

26 Sinicrope FA, Ruan SB, Cleary KR, et al. bcl-2 and p53 oncoprotein expression during colorectal tumorigenesis. Cancer Res 1995;55:237-241.

27 Khosla S, Patel VM, Hay ID, et al. Loss of heterozygosity suggests multiple genetic alterations in pheochromocytomas and medullary thyroid carcinomas. J Clin Invest 1991;87:1691-1699.

28 Cornelis RS, van Vliet M, Vos CB, et al. Evidence for a gene on 17p13.3, distal to TP53, as a target for allele loss in breast tumors without p53 mutations. Cancer Res 1994;54:4200-4206.

29 Beghelli S, Pelosi G, Zamboni G, et al. Pancreatic endocrine tumours: evidence for a tumour suppressor pathogenesis and for a tumour suppressor gene on chromosome 17p. J Pathol 1998;186:41-50. 